\title{
The gene for hereditary multiple exostoses does not map to the Langer-Giedion region (8q23-q24)
}

\author{
Martine Le Merrer, Kamel Ben Othmane, Victor Stanescu, Stanislas Lyonnet, \\ Lionel Van Maldergem, Ghislaine Royer, Arnold Munnich, Pierre Maroteaux
}

Unité de Recherches sur les Handicaps Génétiques de l'Enfant, U12 INSERM, Hópital des Enfants Malades, 149 rue de Sèvres, 75743

Paris Cedex 15, France.

M Le Merrer

$\mathrm{K}$ Ben Othmane

$S$ Lyonnet

G Royer

A Munnich

\section{URA 584 CNRS,} Hópital des Enfants Malades, 149 rue de Sèvres, 75743 Paris Cedex 15, France.

V Stanescu

P Maroteaux

Centre de Génétique de Loverval, Institut de Morphologie

Pathologique, 41 allée des Templiers, 62270 Loverval, Belgium. L Van Maldergem

Correspondence to Dr Le Merrer

Received 15 January 1992. Revised version accepted 9 March 1992.

\begin{abstract}
Hereditary multiple exostoses is a dominantly inherited skeletal disorder which alters enchondral bone during growth and is characterised by exostoses of the juxtaepiphyseal regions. Using polymorphic DNA probes, we have been able to exclude the disease gene from close proximity to the 8q24.1 region where a dominant syndrome with multiple exostoses, the trichorhinophalangeal syndrome type II (TRP II, Langer-Giedion syndrome, MIM 15025), has been previously localised (pairwise linkage $Z=-8.96$ at $\theta=0$ with probe $L 48$ at locus D8S51). Multipoint linkage analysis using probes $\mathrm{L} 48$, L24, and L1 consistently excluded the HME gene from a large area of the distal long arm of chromosome 8, spanning the smallest region of overlap assigned to the TRP II gene. These studies support the clinical view that HME and TRP II are distinct entities.

( $f$ Med Genet 1992;29:713-5)
\end{abstract}

Hereditary multiple exostoses (HME, MIM 13370) is an autosomal dominant skeletal disorder with altered enchondral bone development. It is characterised by exostoses usually arising in the juxtaepiphyseal region of the long bones and sometimes the pectoral and pelvic girdles, ribs, and rarely the vertebrae. ${ }^{1}$ Interestingly, a strikingly different autosomal dominant disease, trichorhinophalangeal syndrome type II (Langer-Giedion syndrome, TRP II syndrome, MIM 15025), is associated with multiple exostoses. The syndrome also includes characteristic facial features, namely pear shaped nose, tented alae, sparse hair, cone shaped epiphyses, mild microcephaly, and mental retardation. In contrast, no exostoses are present in TRP I syndrome (MIM 19035). Considering the phenotypic overlap between the three syndromes, Bühler and Malik ${ }^{2}$ suggested that HME, TRP I, and TRP II might either be expressed by contiguous genes or represent various allelic forms of one single genetic entity, especially as deletions of the long arm of chromosome 8 (8q23-8q24.1) have been reported in both TRP II and TRP I syndromes. ${ }^{3-9}$

Along the same lines, Ogle et $a l^{10}$ recently described a balanced reciprocal translocation $t(8 ; 11)(q 24.1 \mathrm{p} 15.5)$ in a woman presenting with clinical features of HME. This interesting observation provides additional support for the view that the gene for HME might map on the long arm of chromosome 8 as well. In this study we tested six large HME pedigrees for linkage to the TRP II locus, using polymorphic DNA probes derived from the microdissected q23-q24 region of chromosome $8,{ }^{11}$ and provide evidence for exclusion of the HME gene from close proximity to the TRP locus.

\section{Patients and methods}

In recent years, 166 new cases of HME have been observed in the Hôpital des Enfants Malades. Out of the 28 families with at least three affected subjects, six families were selected for their informativeness (47 subjects including 25 affected) (fig 1).

The criterion for diagnosis of HME syndrome was the observation of at least two exostoses of the juxtaepiphyseal regions of the long bones. Exostoses associated with metachondromatosis (MIM 15625) were excluded from the study.

Owing to the existence of latent forms of HME, family studies usually included radiography of the knees. Children under 3 years were excluded because of delayed expression of the disease. A $20 \mathrm{ml}$ EDTA blood sample was collected from each of the 47 subjects. DNA was extracted from lymphocyte pellets by SDS lysis, proteinase $\mathrm{K}$ digestion, phenol/ chloroform extraction, ethanol precipitation, and Tris-EDTA resuspension. Restriction digests of genomic DNA were performed for four hours in buffer supplied by Boehringer. DNA fragments were separated by horizontal gel electrophoresis in TEA buffer, stained with ethidium bromide for visual inspection, and denatured in situ with $0.25 \mathrm{~mol} / 1 \mathrm{HCl}$. The denatured DNA fragments were transferred onto a nylon membrane (Zetabind, Flo Cuno) using the technique of Southern. The DNA probe was labelled with ${ }^{32} \mathrm{P}$-dCTP by nick translation and purified on a Sephadex G-50 column to remove unincorporated nucleotides. The labelled plasmid was then competitively hybridised to sheared total human DNA to reduce lane background caused by common repeats in the probe. ${ }^{12}$ The mix was then added to $25 \mathrm{ml}$ of the hybridisation solution. Membranes were hybridised in polythene bags overnight at $65^{\circ} \mathrm{C}$. They were washed twice at room temperature in $2 \times$ SSEP and $0.1 \%$ SDS, then washed at $65^{\circ} \mathrm{C}$ in $1 \times$ SEEP and $0 \cdot 1 \%$ SDS. 

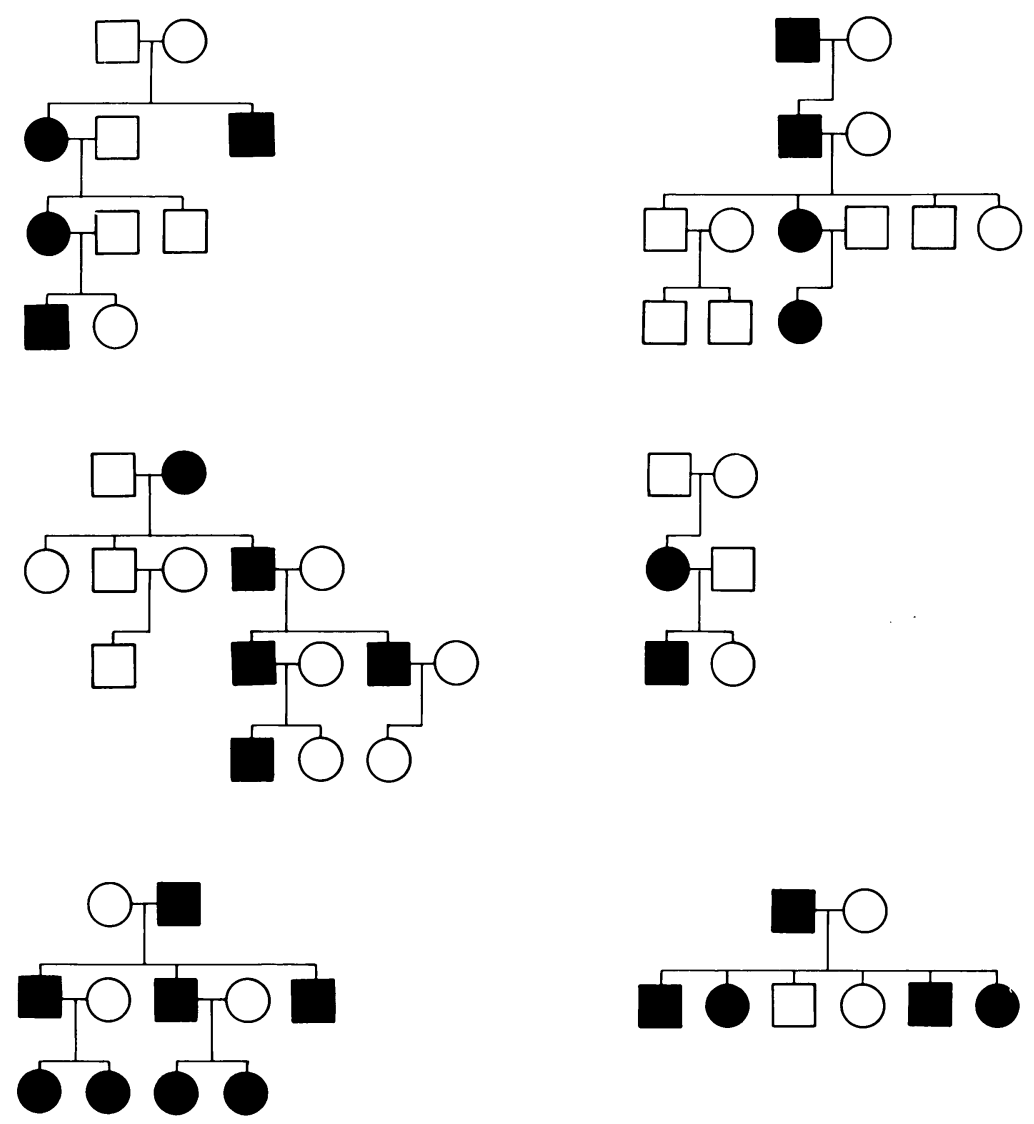

Figure 1 Pedigrees of the HME families studied.

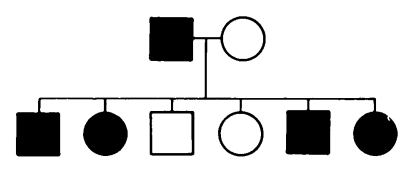

Autoradiographs were obtained by exposure to Kodak X/OMAT films for one to four days at $-80^{\circ} \mathrm{C}$. Polymorphic DNA probes were generated by Hortshemke and Lüdecke ${ }^{11}$ from a 8q24.1 specific microdissection library of the TRP II deletion: L48 (D8S51)SacI, L24 (D8S45)XmnI, and L1 (D8S42)TaqI. Five additional probes located on both sides of the deletion on the long arm of chromosome 8 were also used, namely: PYNM3 at locus $D 8 S 17,{ }^{13} \mathrm{LTII}$ at locus $D 8 S 5,{ }^{14} \mathrm{R} 370$ at locus $D 8 S 25,{ }^{15} \mathrm{~L} 1251$ at locus $D 8 S 29,{ }^{15}$ and MCT128 at locus D8S39. ${ }^{16}$ All these DNA markers showed biallelic RFLPs.

The most likely order of markers was: cen-PYNM3-LT11-L1-L48-L24-Myc-R370L1251-MCT128-tel. Considering the uncertainty of the exact age of onset during growth, a penetrance of 0.90 was arbitrarily assigned. Linkage analysis was performed using the MLINK and LINKMAP options of version $5 \cdot 1$ of the LINKAGE package. ${ }^{17}$

Pairwise linkage analysis of $H M E$ with 8 D DNA markers.

\begin{tabular}{lcrrrr}
\hline & 0 & 0.1 & 0.2 & 0.3 & 0.4 \\
\hline PYMM3 & -4.59 & -0.53 & -0.13 & 0.004 & 0.022 \\
LT11 & -0.39 & -0.06 & 0.02 & 0.04 & 0.02 \\
L1 & 0.40 & 0.29 & 0.19 & 0.11 & 0.05 \\
L48 & -8.96 & -1.37 & -0.49 & 0.11 & 0.02 \\
L24 & 0.047 & 0.33 & 0.35 & 0.29 & 0.17 \\
R370 & 0 & 0.34 & 0.23 & 0.13 & 0.05 \\
L1251 & -4.35 & -0.35 & -0.14 & -0.06 & -0.03 \\
MCT128 & -10.3 & -1.83 & -0.80 & -0.29 & -0.06 \\
\hline
\end{tabular}

\section{Results}

Pairwise linkage showed negative lod score values with probe $\mathrm{L} 48(\mathrm{Z}=-8.96$ at $\theta=0)$, excluding the HME gene from close proximity to the D8S51 locus (table). Multipoint analysis using probes L48, L24, and L1 consistently excluded the HME gene from a relatively large area of the distal long arm of chromosome 8, spanning the smallest region of overlap assigned to the TRP II gene (fig 2). The other probes tested were not informative. However, using probe MCT128, we were able to exclude the HME gene from close proximity to the D8S39 locus, which maps $50 \mathrm{cM}$ distal to the TRP II gene.

\section{Discussion}

In the last few years, HME, TRP I, and TRP II have been regarded as closely related diseases and the hypothesis of either contiguous genes or allelism at a single locus has been discussed. ${ }^{210}$ Here, we exclude the HME gene from close proximity to the TRP II locus in six autosomal dominant families with multiple exostoses. The present data tend to favour the view that HME and TRP are clearly distinct entities. These results are not really surprising as a number of clinical, radiological, and laboratory features allow differentiation of the three conditions.

First, neither facial dysmorphism nor ectodermal dysplasia are present in HME, while those are consistent features in TRP syndrome. Similarly, the clinical progression of exostoses stops at the end of growth in HME while it may continue throughout adult life in TRP II, resulting in severe orthopaedic complications. Secondly, radiological features are also different in the two conditions. Metaphyseal exostoses, for instance, are pediculated in HME, while in TRP II they are more sessile. Whatever the type, the association of exostoses with shortness of the ulna, fibula, and metacarpals is more specific of HME disease, while cone shaped phalangeal epiphyses are characteristic of TRP II. ${ }^{18}$ Finally, the histopathological aspects of the cartilage are strikingly different. ${ }^{19}$ In HME, the exostoses are covered by thickened periosteum that closely adheres to the cartilaginous cap. It arises in contact

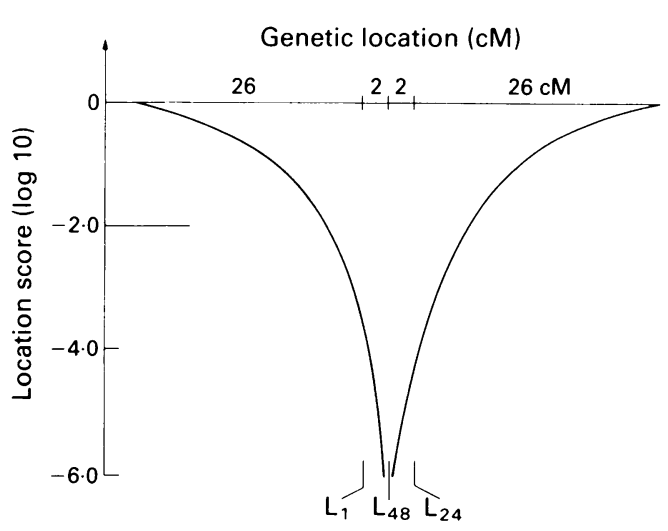

Figure 2 Multipoint linkage analysis in HME. The location score is defined as twice the natural logarithm of the odds ratio. 
with the columns of growth cartilage, which are in abnormal orientation at the periphery (fig 3). In contrast, in TRP II, the exostoses seem to arise as nodules linked to the cartilage of the epiphysis by a pedicle and the cells are voluminous, rich in glycogen, and arranged in ovoid groups (fig 4). Ultrastructural studies show inclusions in chondrocytes and numerous vesicles in the cytoplasm of the osteoblasts.

In conclusion, the genetic data presented here support the clinical view that HME and TRP are probably distinct entities, especially as no deletion of chromosome $8 \mathrm{q}$ has been hitherto reported in cells cultured from exostoses. ${ }^{20}$ Nevertheless, the observation of Ogle et $a l^{10}$ suggests that this condition might be heterogeneous and future linkage studies will

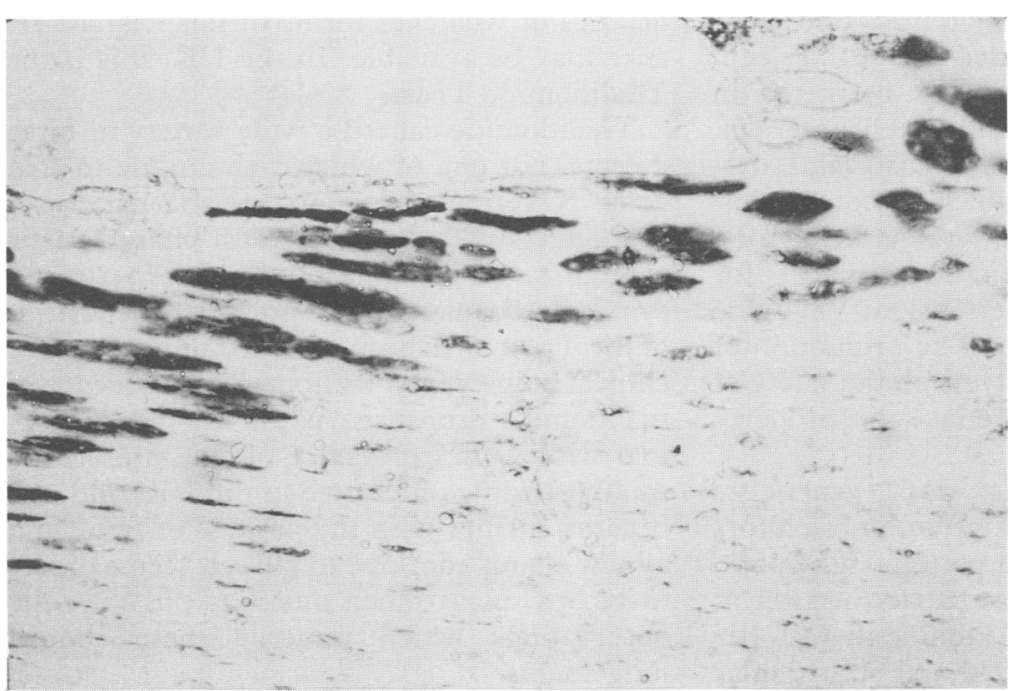

Figure 3 Hereditary multiple exostoses (frozen section $7 \mu$, Azure A pH 2 staining). The growth cartilage columns have an abnormal orientation on the periphery of the cartilage.

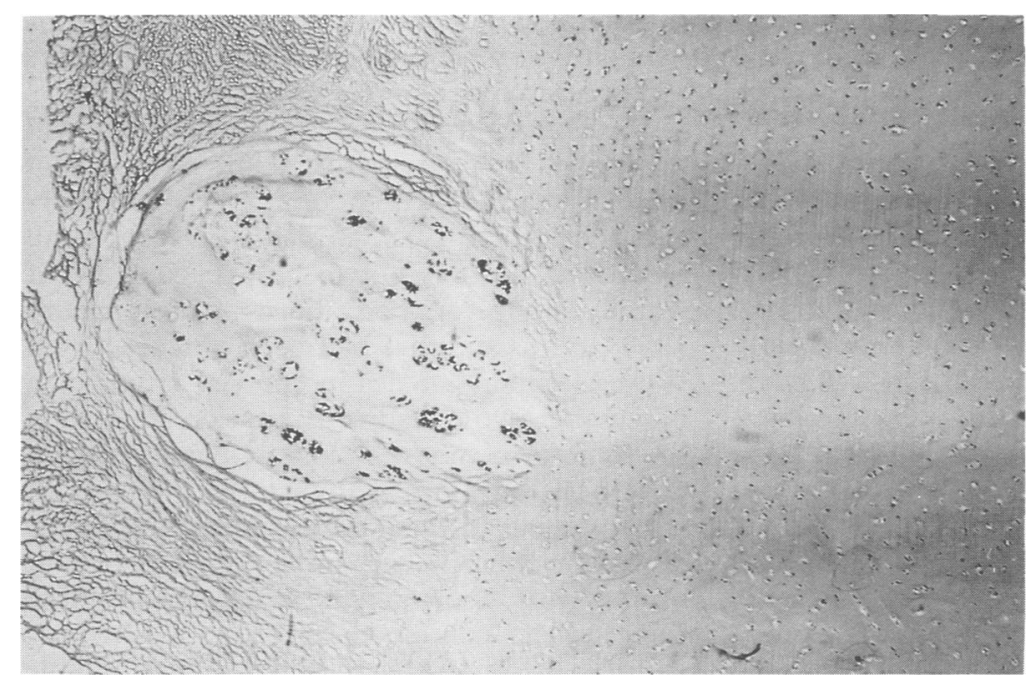

Figure 4 TRP II syndrome (frozen section $7 \mu, P A S$ staining). Cartilage nodule containing groups of large cells, situated under the perichondrium of the epiphysis. hopefully contribute to the mapping of the gene(s) responsible for hereditary multiple exostoses.

\section{Addendum}

Three new families with HME were tested by D8S51 (L48). One family was not informative and in the other two a recombination in each was found. Pairwise linkage analysis showed a negative lod score with probe L48 at $\mathrm{Z}=-18 \cdot 32$ at $\theta=0$.

We thank Bernhard Horsthemke for kindly providing probes of the Langer-Giedion region. We thank Gisèle Gal and Alan Strickland for their help in preparing this manuscript. This work was supported by Association Française contre les Myopathies (AFM).

Hennekam RCM. Hereditary multiple exostoses. $f \mathrm{Med}$ Genet 1991;28:262-6.

2 Bülher EM, Malik NJ. The tricho-rhino-phalangeal syndrome(s): chromosome 8 long arm deletion: is there a shortest region of overlap between reported cases? TRP I and TRP II syndromes: are they separate entities? $A m \mathcal{F}$ Med Genet 1984;19:113-9.

3 Bülher EM, Bülher UK, Beutler C, Fessler R. A final word on the tricho-rhino-phalangeal syndromes. Clin Genet 1987;31:273-5.

4 Goldblatt I Smart RD. Tricho-rhino-phalangeal syndrome without exostoses, with an interstitial deletion of $8 \mathrm{q} 23$. Clin Genet 1986;29:434-8.

5 Hamers A, Jongbloet P, Peeters G, Fryns JP, Geraedts J. Severe mental retardation in a patient with tricho-rhinophalangeal syndrome type $\mathrm{I}$ and $8 \mathrm{q}$ deletion. Eur $\mathcal{f}$ Pediatr 1990;149:618-20.

6 Langer LO, Krassikoff N, Laxova R, et al. The trichorhino-phalangeal syndrome with exostoses (or LangerGiedion syndrome : four additional patients without mental retardation and review of the literature. $\mathrm{Am} \mathcal{F} \mathrm{Med}$ Genet 1984;19:81-111.

7 Pfeiffer RA. Langer-Giedion syndrome and additional congenital malformations with interstitial deletion of the long arm of chromosome 8: 46XY, del 8(q13-q22). Clin Genet 1980;18:142-6.

8 Turleau C, Chavin-Colin F, de Grouchy J, Maroteaux P, Rivera H. Langer-Giedion syndrome with and without del 8q. Assignment of critical segment to $8 \mathrm{q} 23$. Hum del 8q. Assignment

9 Yamamoto $Y$, Oguro N, Miyao M, Yanagisawa $M$. Trichorhino-phalangeal syndrome type I with severe mental retardation due to interstitial deletion of 8q23.3-24.13. Am f Med Genet 1989;32:133-5.

10 Ogle RF, Dalzell P, Turner G, Wass D, Yip MY. Multiple exostoses in a patient with $\mathrm{t}(8 ; 11)(\mathrm{q} 24.11 ; \mathrm{p} 15.5)$. $\mathcal{F}$ Med Genet 1991;28:881-3.

11 Horsthemke B, Ludecke HJ. Physical mapping of the Langer-Giedion syndrome chromosome region (LGCR, 8q241). HGM 11 Abstracts, 1991.

12 Sealey PG, Whittaker PA, Southern EM. Removal of repeated sequences from hybridization probes. Nucleic Acids Res 1985;13:1905-22.

13 Nakamura Y, Martin C, Leppert M, et al. Isolation and mapping of a polymorphic DNA sequence PYNM3 on mapping of a polymorphic DNA sequence PYN

14 Dietzseh E, Retief AE, Warnich L, et al. An anonymous human single copy genomic clone (D8S5) (TLII) on chromosome 8 identifies a moderately frequent RFLP. Nucleic Acids Res 1986;14:6781.

15 Donis-Keller H, Green P, Helms C, et al. A genetic linkage map of the human genome. Cell 1987;51:319-37.

16 Nakamura Y, Carlson M, Krapcho $K$, et al. Isolation and mapping of polymorphic DNA sequence (pMCT 128.2) on chromosome 8. Nucleic Acids Res 1988;16:3590.

17 Lathrop G, Lalouel M, Julier JM, Ott J. Multilocus linkage analysis in humans; detection of linkage and estimation of

18 Maroteaux P. Maladies osseuses de l'enfant. Paris: Editions Flammarion Médecine-Sciences, 1982.

19 Stanescu V, Stanescu R, Maroteaux P. Etude morphologique et biochimique du cartilage de croissance dans les
chondrodysplasies. Arch Fr Pediatr 1977;34(suppl 2):180.

20 Hall JG, Wilson RD, Kalousek D, Beauchamp R. Familial multiple exostoses. No chromosome 8 deletion observed. Am $\mathcal{F}$ Med Genet 1985;22:639-40. 